\title{
LXXVI. Account of a new cyanide of gold
}

\section{Mr. John Carty}

To cite this article: Mr. John Carty (1844) LXXVI. Account of a new cyanide of gold, Philosophical Magazine Series 3, 24:162, 515-516, DOI: $10.1080 / 14786444408644915$

To link to this article: http://dx.doi.org/10.1080/14786444408644915

$$
\text { 册 Published online: } 30 \text { Apr } 2009 .
$$

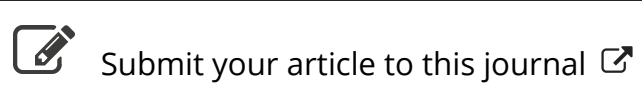

\footnotetext{
山 Article views: 2
}

Q View related articles $\sqsubset$ 
LXXVI. Account of a new Cyanide of Gold. By $M r$. John CarTY*.

THERE is one compound of cyanogen and gold known at present to chemists; it is a tercyanide, or contains 3 equivalents of cyanogen combined with one of gold. Having observed indications of a protocyanide, and not finding it mentioned in the chemical works usually referred to, I tried to obtain it pure, and have, I believe, succeeded by the following method:-

Protochloride of gold was decomposed by cyanide of potassium in solution. An abundance of a yellow matter appeared at first, but an excess of the cyanide gave a clear and perfect solution. To this solution muriatic acid in excess was added; on boiling a bright yellow powder precipitated, which was washed and dried by a moderate heat. It was insoluble in water, alcohol and æther; soluble in ammonia and in solution of cyanide of potassium. It was decomposed by heat, like a cyanide, and nothing but cyanogen gas was driven off. It was not decomposed by strong boiling muriatic or nitric acid, or by a solution of chlorine, but was decomposed, though not rapidly, by hot nitro-muriatic acid, and very slowly by solution of potash; boiling sulphuric acid liberated metallic gold.

30.7 grains of the yellow powder were heated to redness in the air, 27.0 of gold remained, $3 \cdot 7$ of cyanogen were therefore driven off. Other experiments on smaller quantities agreed closely with this, and they show the yellow substance to have been composed as near as may be of 200 of gold and 26 of cyanogen; and it is therefore a protocyanide of gold.

When tercyanide of gold was dissolved in boiling muriatic acid, and the solution concentrated, protocyanide of gold was gradually deposited as a yellow powder. 2 atoms of cyanogen were removed, probably by forming ammoniacal compounds with the elements of the water which is present.

The protocyanide of gold was dissolved in hot ammonia; on cooling an abundance of gray glistening plates fell, which were found to be a compound of the protocyanide and ammonia. The ammonia was easily removed by a gentle heat, or by hot muriatic acid leaving the protocyanide.

Protocyanide of gold was dissolved in solution of cyanide of potassium. By evaporating the liquid, long prismatic white crystals, nearly opake, anhydrous and somewhat deliquescent, were obtained. They were decomposed by heat into gold, cyanogen gas and cyanide of potassium. A solution of them was not soon affected by muriatic acid in the cold,

* Communicated by the Chemical Scciety; having been read February 19,1844 . 
but on boiling the liquid for a minute or two protocyanide of gold was precipitated, and no gold remained in solution. By analysis it appeared to consist of one equivalent of protocyanide of gold with 2 of cyanide of potassium*.

From these experiments we may conclude,-1. That there is a protocyanide of gold remarkable for being the most stable of all the cyanides, except perhaps cyanide of palladium. 2. That tercyanide of gold is reduced to protocyanide by boiling muriatic acid. 3. That the protocyanide combines with ammonia and with cyanide of potassium.

\section{Proceedings of Learned Societies.}

ROYAL ASTRONOMICAL SOCIETY.

[Continued from p. 308.]

December 8, TTHE following communications were read:-I. On 1843. I the Apparent Magnitudes of the Fixed Stars. By C. Piazzi Smyth, Esq. Communicated by Captain W. H. Smyth, R.N.

The author complains of the want of information on the methods of observing the apparent magnitudes of the stars, and of the little attention which has been paid to the proposal of a prize for a successful photometer (Memoirs, vol. i. p. 507), by the Astronomical Society.

He proposes to employ telescopic vision, and to measure the degrees of brightness of every star by means of the obscuration which is necessary to make it vanish. By this means, the necessity of direct comparison between stars taken two and two is avoided, and an absolute zero is established.

For producing the obscuration, he proposes, in the first place, a long wedge of blue coloured glass (with its prismatic qualities counteracted by a similar transparent wedge), made to slide between the object and eye-glasses, a little way out of focus. This wedge might be fixed on the eye end of the telescope, mounted either in a micrometer frame, or made to move in the manner of a barometer scale.

Another plan is, to have a coloured disc of glass in the tube, capable of sliding up and down in it, by which means the object will be differently obscured, on account of the variation of the diameter of the pencil of rays at different distances.

The author then dwells on the method of observation, the means of getting rid of the atmospheric effect, the establishment of a common unit of comparison, and the obviation of the practical difficulty of obtaining a uniform rate of obscuration.

* After the reading of this paper before the Chemical Society, a paper on the same cyanide of gold, by Messrs. Glassford and Napier, was read, in which the composition of the double cyanide of potassium and gold was stated to be 1 eq. of protocyanide of gold, 1 of cyanide of potassium and 1 of water, and on carefully repeating my analysis I found their statement to be correct. 